\title{
The effects of incivility on nursing education
}

\author{
Amy Schaeffer \\ Shepherd Univeristy, Shepherdstown, USA \\ Email: $\underline{\text { amyshroades@yahoo.com }}$ \\ Received 31 March 2013; revised 30 April 2013; accepted 15 May 2013 \\ Copyright (C) 2013 Amy Schaeffer. This is an open access article distributed under the Creative Commons Attribution License, which \\ permits unrestricted use, distribution, and reproduction in any medium, provided the original work is properly cited.
}

\begin{abstract}
Incivility in the population has become of great interest within the past decade, particularly in the wake of the school massacre in Columbine and the recent movie theatre mass murder in Aurora, Colorado. While citizens struggle to make sense of these violent behaviors, higher education officials are perhaps most vested in exploring the causes, displays, and solutions to uncivil behavior among both faculty and students. The effects of incivility, whether classified as minor disruptions or major violence, may affect the student nurse and impede his or her progress and ability to become an empathic nurse, which is a goal of nursing education. Academic incivility may contribute to bullying in the workplace, which has been identified as a cause of attrition and contributes to the national nursing shortage. This article describes the effects of uncivil behavior on nursing faculty and students and the effect this may have on the nursing workforce.
\end{abstract}

Keywords: Incivility

\section{BACKGROUND}

The ability to foster an atmosphere of civility on college campus is often elusive [1]. Clark and Springer describe "civility" as being polite, respectful and decent. On the contrary, "uncivil" behavior is identified as speech or action that is disrespectful or rude and may range from insulting remarks and verbal abuse to explosive, violent behavior [1]. In academia, this can be construed as any behavior which disrupts or impedes the learning environment. The causes of this type of behavior have been attributed to cultural and societal norms, such as increased traffic, noise, crowding and crime [2]. In a cultural context, many believe that anger is unavoidable, an instinctive drive, and uncontrollable, thus excusing the behavior when it occurs [2]. According to Thomas, it is commonplace to see inappropriate anger displayed in popular culture, such as television, music, movies, and video games, and aggressive role models who seem to have little or no penalties, even for violent acts much outside the scope of acceptable, legal behavior. It is with little surprise that violence seems to be increasing on college campuses, as well as all aspects of uncivil behavior [2] Maladaptive anger behavior is a significant problem in nursing education that not only interferes with studentfaculty relationships, but also is significantly disruptive to student learning and desire to learn.

Generational divides further compound this problem, with most Generation X and Y students being described as "self-absorbed generations of slackers who have a short attention span and a lack of work ethic" [2]. While this is certainly a subjective generalization and not true of all students, it is a phenomenon which contributes to student and faculty expectations, hostility, anger, and maladaptive expression of that anger.

Behaviors most commonly cited by faculty in Clark and Springer's 2008 survey, which included 324 nursing students, were "making disparaging groans", making sarcastic remarks or gestures, not paying attention in class, cheating on examinations, using cell phones during class, and dominating class discussions [3].

According to Clark and Springer, the frequency and intensity of student incivility has increased to include verbal abuse such as name calling, yelling at faculty or other students, and even engaging in physical contact. Due to the increase in the frequency and severity of these incidents, it is important to examine how this affects nursing education and those who provide and partake in it.

Nursing faculty is vulnerable to the effects of student incivility as well, ranging from rudeness to actual physical assault and loss of life [4]. Clark and Springer (2007) list various ways that they encounter incivility, most of them being non-physically violent but considered uncivil nonetheless: arriving to class late, leaving class early, refusing to answer questions, rudely contesting test answers, and being unprepared for class. These factors have 
been shown to significantly invoke anxiety, self-doubt, and anger in nursing faculty [2].

While many factors related to academic incivility have been cited, including desensitization to violence via media, inadequate secondary school education, and absent or inadequate parenting, the faculty has rarely viewed themselves as a source of conflict [5]. This is of great interest because according to a study conducted by JM Hall (2004), nursing faculty themselves may create a situation that dehumanizes nursing students, leading to student defensiveness, anxiety, and inability to moderate angry feelings. Clark's 2007 study identified factors that led to student perception of faculty incivility, which included behaviors that resulted in three themes: 1 ) the belittling and demeaning nature in which the faculty addresses students; 2) student favoritism including being treated subjectively; and 3) the pressure to conform to faculty demands that are not within the student's capability. According to Clark, students also reported that intimidation over time tended to cause actual psychological and physiological symptoms, including anxiety, depression, gastro-intestinal distress, mood disorders, and other physical ailments. Uncivil behavior by nursing faculty is morally distressing and confusing to students, who are taught through curriculum that nursing is a profession that is founded on the principle of caring [5].

\section{LITERATURE REVIEW}

Clark's 2008 study was a qualitative research that queried insight from students on faculty incivility and applied the concept of Rankism, which she defined as "the abuse of power and rank to disadvantage another". Clark asserts that achieving rank and position within academia is a legitimate, expected goal of higher education; however, the abuse of rank by faculty and administrators cause catastrophic problems that undermine the mission of nursing schools. Rankism is a prejudicial concept that can be compared to racism, sexism, and ageism, where a more powerful group uses their power to an unfair advantage.

In the phenomenological Clark study, students who were subjected to uncivil behaviors by faculty described their experiences and encounters in various ways, all of them with emotional intensity, and some of the encounters had been years before. Clark asserts that some students described psychological symptoms that included feeling hopeless, helpless, or emotionally traumatized. Information ascertained from the students reveal that they felt powerless to combat the faculty's uncivil behavior, as they felt they may be penalized for speaking out against such behaviors [5].

Clark utilized Robert Fuller's concept of Rankism to suggest ideas that may promote dignitarian values. The suggestions for combating the phenomenon of Rankism include "breaking the taboo": recognize that rank is an issue, talk about it openly, and listen to the thoughts and feelings of others. Fuller also called for a need for transparency, as secrecy, favoritism, and suspicion tend to accompany Rankism. Fuller advocated for a program or organization that facilitated questions and protected those who dissented. In this manner, nursing faculty can role model behavior that teaches respectful social dissent, and honor concepts of cultural awareness, tolerance, and non-discriminatory practice. Clark's work using Fuller's concept on Rankism also suggests that delegation be indigenous in every nursing program so as to distribute power and prevent situations in which one authority of higher rank holds all the power.

In 2004, Clark studied 36 nursing faculty and 467 nursing students in a survey on the areas of student and faculty incivility. All participants completed the incivility in nursing survey, which included demographic data and utilized quantitative measures as well as qualitative measures. Instruments were used that were derived from the University Center for Survey Research. The authordeveloped questionnaire was reviewed by faculty for content validity. The quantitative measure reviewed uncivil behaviors and the degree to which they were considered to be uncivil. The survey listen sixteen uncivil behaviors, in which respondents used a Likert scale to categorize the degree as to which behaviors were uncivil, as well as the frequency in which they had experienced the uncivil behaviors within the past month.

The student behaviors reported to be most uncivil by both faculty and students was cheating on examinations and quizzes, using cell phones in class, holding distracting conversations, marking sarcastic or inappropriate remarks, sleeping in class, and refusing to answer direct questions [1].

This study also queried students and faculty on faculty behaviors that were considered uncivil. Reported by 295 students was the behavior "Belittling, taunting, sarcasm, humiliation, intimidation or profanity" as the top uncivil behavior displayed by nursing faculty. 222 students reported "being cold or unapproachable" as an uncivil behavior.

According to Clark \& Springer, faculty and student perceptions were compared to see if they viewed the same things as being uncivil by using a row-mean-score test from epidemiology. The findings were that some behaviors were viewed differently by staff and faculty. Interestingly, faculty was less likely than other students to view student behavior as uncivil. Particular behaviors about which faculty members and student perceptions differed included students acting apathetic or bored $(p<$ 0.01 ), students making disapproving or sarcastic groans $(p<0.01)$, and students arriving late to class $(p<0.05)$. 
In this study, the survey was used to determine the degree as to which students and faculty perceived incivility to be a problem. The majority (61.5\%) of respondents, both faculty and students, considered it to be a moderate problem. The study concluded that uncivil encounters have a pervasive negative academic setting and not only disrupt the learning environment, but also leave students unprepared to enter a workforce that is fraught with potential for disputes and conflict [1].

Academic dishonesty has been identified by both faculty and students as "student incivility" [6]. According to Kolanko, Clark, \& Henirch, et al., as many as 70 to 95 percent of students have engaged in intentional practices of deception that involves another's work. The finding of unethical classroom behaviors being related to unethical clinical behavior is disturbing and incongruent with the ethical practices in which the profession of nursing is founded upon [6]. The most frequent unethical clinical findings included infringement of patient confidentiality, taking medical equipment home for personal use, and documentation of medications or treatments that were not provided.

Cultural differences have been cited as causes of perception of incivility as well [6]. The authors propose that students who have immigrated from developing countries where "collective thought" is the norm may have difficulty understanding the concept of plagiarism. The authors conclude that as faculty encounter these types of behaviors that are not acceptable in our academic society, they need to be corrected respectively and in a non-punitive manner [6].

Although incivility is a problem that seems to be happening more and more throughout the United States, according to Kolanko, Clark, \& Heinrich, et al., very little research exists related to faculty experiences with uncivil student behaviors. However, the concept of Bullying is a thoroughly studied phenomenon, and one that occurs in nursing schools as regularly as any other academic institution. This may include direct bullying, such as verbal or physical aggression, or more covert, indirect bullying, such as passive aggressive behaviors and social isolation from a group [6]. The results of bullying are widespread and often long term, including physiological symptoms, anxiety, nightmares, lowered self-esteem, and use of alcohol or drugs to cope. This may contribute to nursing school attrition rates as well, whether the bullying is being done by faculty or students; many victims simply cannot face going back into a bullying situation and don't have the resources to combat bullying. The authors suggest that nursing faculty have frank discussions with nursing students regarding bullying and policies that enforce consequences for bullying.

Faculty incivility plays a major role in contributing to student incivility [6]. Consequences of faculty incivility were identified as impairment of the mentoring role that faculty have an obligation to provide, problematic learning environments, increased potential for violence, and increased stress in students' personal relationships with family and friends [6]. This creates a complex dynamic in which students find themselves resisting and not learning, and faculty finds themselves disciplining instead of mentoring. It is difficult for higher-level learning to take place when such external and internal stressors exist. In Clark's study, students offered suggestions for combating the problem of faculty incivility, including enforcing a campus code of conduct, having zero tolerance policies, and creating an environment where respectful discourse, dissent and discussion is welcomed [6].

This article addressed the issue of collegial incivility as well, which the authors believe to play a part in all other types of academic incivility. While collegial incivilities may be causing faculty to resign and leave their positions, there is little research to support this theory [6]. During a plenary session, nurse faculty were asked to recall a time in which a colleague, administrator, or subordinate did or said something to make the faculty member feel belittled, marginalized, or dismissed. Approximately $25 \%$ of the audience (261 faculty members) had "mean girl" stories to tell, which included things such as name-calling, relational aggression, or social exclusion.

The authors concluded that while there is a wealth of information available in the literature on elementary and secondary education, very little research has been done on student nurse or student faculty bullying, and this topic is timely and ripe for further research [6]. Nursing faculty is a vulnerable population due to the effects of student incivility [4]. The authors propose that while nursing faculty is not typically viewed as a vulnerable population, those who teach are susceptible to psychological, physical, and emotional harm [4]. The authors identified student incivility, aggression and bullying, horizontal violence, and abuse of power by administrators as some of the incivilities that nursing faculty face. Dal Pezzo and Jett concluded that the emotional toll on nursing faculty was significant: reported trouble sleeping, anxiety, low self-esteem, poor morale, absenteeism, and depression. When conflict or tension among peers becomes unbearable, faculty may choose to leave academia, which is a very serious issue considering the lack of available nursing faculty in the United States [4].

While academic integrity has been cited as a major student incivility, it is surprising to realize that discussions about academic integrity are minimal, particularly given that the profession of nursing is one that is founded upon the expectations of trust, honesty, respect, integrity, and responsibility [7]. According to the authors, 253 nursing students were studied for trends in cheating. The survey was a questionnaire with a yes/no response, as 
well as open ended questions asking how students cheat [7]. More than 75 percent of students admitted to cheating, including using "cheat sheets", copying from another student's test answers, writing on body parts, and whispering answers. This study points to a very serious problem of lack of personal integrity, while personal integrity is held as a hallmark of nursing. It would seem a logical assumption that those who would cheat during their academic career may continue this behavior into their working lives [7].

Smith and Schaffer (1995) studied positive and negative relationships between nursing faculty and students and how it affected the learning experience. Their methodology included a sample of two groups: 34 second semester senior students and 12 faculties from two nursing schools in the Midwest. The six problems posed in the mixed survey included inconsistent grading, late paper policies, disagreement about amount of clinical supervision needed, how student complaints were handled, unexpected low grade in clinical, and students' “covering up” for a classmate's incomplete nursing care [8]. The survey revealed that the most common problem for students was inconsistent grading (70.6\%). Students also reflected twice as many barriers to ethical action (mean = 16 ) as did faculty (mean $=6.92$ ). This may reflect their developmental status or is a result of their feeling of decreased power [8]. The implications of this study highlight the need for both students and faculty to be sensitive to identifying and reacting to ethical situations, as well as to incorporate more of the "caring" aspect of nursing into the education of the nursing profession. Attention must be given to barriers which prevent faculty and students from addressing these concerns [8].

\section{DISCUSSION}

While incivility is not a new problem in nursing education, it is an issue that has not been thoroughly researched [8]. Gaps in the literature still exist, including the relationship between unethical or uncivil behavior in the classroom and uncivil behavior in the professional nursing role once the student has graduated.

Current research to date has established that incivility in nursing education is a major distraction to higher learning levels, may contribute to psycho-social problems, physiological ailments, and is a major cause of both nursing student and nursing faculty attrition. Nursing student and faculty attrition is of special concern as there is a shortage of both registered nurses and nursing faculty in the United States, and it is projected by experts to grow larger in the next decade. Further research is needed to discover ways to combat and prevent incivility in nursing education, in order to provide our population with the reputable qualities that the nursing profession holds.

\section{REFERENCES}

[1] Clark, C.M. and Springer, P.J. (2007). Incivility in nursing education: A descriptive study on definitions and prevalence. Journal of nursing education, 47, 7-14.

[2] Thomas, S.P. (2003) Handling anger in the student-teacher relationship. Nursing Education Perspectives, 24, $17-$ 24.

[3] Clark, C.M. and Springer, P.J. (2007) Thoughts on incivility: Student and faculty perceptions of uncivil behavior in nursing education. Nursing Education Perspectives, 28 93-97.

[4] Dalpezzo, N. and Jett, K. (2010) Nursing faculty: A vulnerable population. Journal of Nursing Education, 49, 132-135. doi:10.3928/01484834-20090915-04

[5] Clark, C.M. (2008) Student perspectives on faculty incivility in nursing education: An application for the concept of Rankism. Nursing Outlook, 56, 4-8. doi:10.1016/j.outlook.2007.08.003

[6] Kolanko, K.M., Clark, C., Heinrich, K.T., Olive, D., Serembus, J.F. and Sifford, K.S. (2006) Academic dishonesty, bullying, incivility, and violence: Difficult challenges facing nurse educators. Nursing Education Perspectives, 27, 34-42.

[7] Tippitt, M., Ard, N., Kline, J., Tilghman, J., Chamberlain, J. and Meagher, P. (2009) Creating environments that foster academic integrity. Nursing Education Perspectives, 30, 239-244.

[8] Schmitz, K. and Schaffer, M. (1995) Ethical problems encountered in the teaching of nursing: Student and faculty perceptions. Journal of Nursing Education, 34, 42-44. 